\title{
Covid-19: experts question analysis suggesting half UK population has been infected
}

\author{
Anna Sayburn \\ London
}

Experts have criticised an unpublished modelling study released to the media on Tuesday 24 March that suggested that half the UK population might already have been infected with covid-19. ${ }^{1}$

They emphasised that even if the modelling turned out to be correct it would not change the current public health advice to reduce the spread of the virus.

The study, from the Nuffield Department of Medicine at the University of Oxford, used data on the number of deaths and reported cases in the early stages of the epidemic in Italy and the UK. The researchers used mathematical modelling to estimate infection rates by fitting a

"susceptible-infected-recovered" model of epidemics to the numbers of deaths seen.

The modelling made assumptions about the proportion of the population at risk of death or severe illness, the basic reproduction number of the virus, the period of time during which people are infected, and the time from infection to death The researchers showed outcomes generated from different assumptions, including a reproduction number of 2.25 and 2.75, and setting the proportion of the population at risk of death or severe disease at $1 \%$ or $0.1 \%$.

They said that the UK data indicated that by 19 March (15 days after the first reported UK death) between $36 \%$ and $68 \%$ of the UK population would have been infected, depending on the assumptions used. In addition, their figures suggested that the current epidemic "should have an approximate duration of two to three months," they said.

Commentators pointed to a number of "key failings" that may undermine the study, which has not yet been peer reviewed or published in a journal.

Neil Ferguson, director of the MRC Centre for Global Infectious Disease Analysis at Imperial College London, was asked about the study when he appeared before a parliamentary select committee hearing on 25 March. It was his analysis that showed that without physical distancing there would be 260000 deaths in the UK from covid-19 and that led to change in government policy. $^{2}$

Ferguson said, "We've been analysing data from a number of Italian villages at the epicentre for the last few weeks where they did a viral swab on absolutely everybody in the village at different stages of the outbreak. ${ }^{3}$ And we can compare that with official case numbers, and those data all point to the fact that we are nowhere near the Gupta [the Oxford analysis] scenario in terms of the extent of the infection."
Paul Hunter, professor in medicine at the University of East Anglia, said that the simple model "assumes complete mixing of the population," which is "almost always wrong" at a country level. "We do not all have an equal random chance of meeting every other person in the UK." He said that reproduction number was a "very clumsy" measure of how disease spreads, which is likely to change over time. He also criticised the researchers' assumption that only a very small proportion of the population was at risk of being admitted to hospital because of the disease.

"This is a big assumption and it is far too early in the epidemic to know what this value is," he said.

The researchers and the experts agree on the need for serological studies in areas affected by the epidemic. Testing serological immune response would show how many people have been exposed to the virus.

The researchers said in the study, "Urgent development and assessment of such tests should be followed by rapid implementation at scale to provide real-time data."

James Naismith, director of the Rosalind Franklin Institute at the University of Oxford, backed the call for widespread testing. "This will be necessary to test the paper's hypothesis. The need for, the science behind, and plans to implement such serological testing are accepted and moving forward across the globe," he said. He warned that this would "take time."

He added, "At this moment, nothing in [this] paper calls for or could be used to justify any change in current policy; that is, unless we all follow the current government advice on social distancing, the UK will see many thousands of deaths that could have been avoided."

Mark Woolhouse, professor of infectious disease epidemiology at the University of Edinburgh, said that the possibility that large numbers of people have already been infected but remain asymptomatic was "hypothesis rather than fact."

He said that, if it were correct, "that would not change current policy in the UK, which is focused on reducing the short term impact of the epidemic on the NHS." It would, however, "change enormously our long term expectations" and suggests that the threat of covid-19 worldwide would diminish in coming months.

\footnotetext{
Lourenco J, Paton R, Ghafari M, et al. Fundamental principles of epidemic spread highlight the immediate need for large-scale serological surveys to assess the stage of the SARS-COV-2 epidemic. https://www.dropbox.com/s/oxmu2rwsnhigj9c/Draft-COVID-19Model\%20\%2813\%29.pdf.

2 Mahase E. Covid-19: UK starts social distancing after new model points to 260000 potential deaths. BMJ 2020;368:m1089. 10.1136/bmj.m1089 32184205
} 
3 Day M. Covid-19: identifying and isolating asymptomatic people helped eliminate virus in Italian village. BMJ 2020;368:m1165. 10.1136/bmj.m1165 32205334
Published by the BMJ Publishing Group Limited. For permission to use (where not already granted under a licence) please go to http://group.bmj.com/group/rights-licensing/ permissions 